\title{
Assessing Internet-Based Information used to aid patient decision-making for pelvic exenteration for locally advanced and recurrent rectal cancer
}

\author{
Anwen Williams ( $\nabla$ drawilliams@hotmail.co.uk) \\ Abertawe Bro Morgannwg University Health Board https://orcid.org/0000-0002-8521-9989 \\ Andrew Cunningham \\ Abertawe Bro Morgannwg University Health Board \\ Hayley Hutchings \\ Swansea University Medical School \\ Dean A Harris \\ Abertawe Bro Morgannwg University Health Board \\ Deena Harji \\ Newcastle University Institute for Health and Society \\ Martyn D Evans \\ Abertawe Bro Morgannwg University Health Board
}

\section{Research article}

Keywords: Internet based information, Google, Patient Decision Aid, Pelvic Exenteration, Rectal Cancer, Locally Advanced Rectal Cancer, Locally Recurrent Rectal Cancer, DISCERN, IPDAS, Quality of Health Literature

Posted Date: August 17th, 2020

DOI: https://doi.org/10.21203/rs.3.rs-59146/v1

License: (c) (i) This work is licensed under a Creative Commons Attribution 4.0 International License. Read Full License 


\section{Abstract}

Background: To establish what online decision aids are currently available for patients contemplating pelvic exenteration (PE) for locally advanced and recurrent rectal cancer (LARC and LRRC).

Methodology: A grey literature review was carried out using the Google Search ${ }^{\mathrm{TM}}$ engine undertaken using a predefined search strategy (PROSPERO database CRD42019122933). Written health information was assessed using the DISCERN criteria and International Patient Decision Aids Standards (IPDAS) with readability content assessed using the Flesch-Kincaid score.

Results: Google search yielded 27,782,200 results for the predefined search criteria. 131 sources were screened resulting in the analysis of 6 sources. No sources were identified as a decision aid according to the IPDAS criteria. All sources were deemed acceptable quality of written health information, scoring a global score of 3. for the DISCERN written assessment. The median Flesch-Kincaid ease was 50.85 (32.5-80.8) equating to a reading age of 15-18 years.

Conclusions: This study has found that there is a paucity of online information for patients contemplating PE. Sources that are available are aimed at a high health literate patient. Given the considerable morbidity associated with this surgery there is a desperate need for high quality relevant information in this area. We would suggest the development of a PDA to improve decision making and ultimately improve patient experience.

\section{Background}

In the UK, 14,000 new cases of rectal cancer are diagnosed every year with an estimated 704,000 new cases worldwide in 2018 (1), of which 5-10\% are locally advanced (LARC) at presentation $(2,3)$. The incidence of locally recurrent rectal cancer (LRRC) after treatment is 4-8\% (4-6). Without treatment the prognosis for both LARC and LRRC is poor, with median survival estimated at less than 1 year and only $5 \%$ of patients surviving 5 years $(7,8)$. Pelvic exenteration (PE) represents the only potentially curative option in this patient group. who would otherwise only be suitable for palliative intervention. Complete oncological resection (R0) confers the greatest survival benefit $(9,10)$ with survival rates of $40-50 \%$ at 5 years $(11-15)$.

Whilst PE is the only potentially curative treatment option, it is associated with a significant risk of mortality of up to $25 \%$ (median $2.2 \%$ ) and morbidity of up to $100 \%$ (median $57 \%$ ) (8). Whilst the surgical and oncological outcomes have been well reported, there is a paucity of research on survivorship and the psychological impact of exenterative surgery (8) despite the growing number of PE survivors dealing with the effects of radical surgery (16-18).

Shared Decision Making (SDM) between patients and clinicians represents the epitome of patient-centred care. Analysing and understanding evidence-based medicine whilst ensuring that the patient's intentions, values and preferences are considered during the decision-making process are fundamental to SDM. A good decision is one that is informed, consistent with personal values, acted upon and with which patients are satisfied (19). For patients to be able to perform part of the integral decision they need clear, evidence based patient information (EBPI) that is easy to understand, informative and discusses the treatment options that include supportive care (20). The Royal College of Surgeons of England (RCSEng) encourage surgeons to allow sufficient time for patients to read further material on their condition and available treatment, including accessing online information (21). It has been demonstrated that around two-thirds of patients use the internet to seek health information $(22,23)$. Previous work has shown the majority of patients choose GoogleTM as an initial starting point when looking for online health information (24). The internet provides patients with a platform to search for disease-related information, supportive communication, practical tips on living with cancer, to find out more about their disease and other general health issues, and to search 
for information regarding diagnosis and treatments (25-27). The internet is an extensive and complex source of information however, all pages do not go through a peer review process and can therefore vary in quality and consistency.

Whilst the principles of SDM are well documented, guidance about the integration into routine clinical practice is limited. One method is to use patient decision aids (PDA). Fundamentally, PDAs provide choice, describe treatment options and assist patients in exploring their preferences to enable decisions. They therefore support a process of deliberation and aid understanding of decisions that should be influenced by what matters most to patients as individuals to develop informed preferences (28).

Given the complexity of the decision to undergo a PE, a PDA appears to be a suitable method to introduce SDM for this cohort of patients. The aim of this study was to review the presence and quality of current PDAs including internet resources available to LARC/LRRC patients contemplating PE.

\section{Methodology}

This review was carried out in accordance with Preferred Reporting Items for Systematic Reviews and Meta-analyses (PRISMA) guidelines. This literature search was registered on the PROSPERO database CRD42019122933 (29).

The Decision Aid Library Inventory (DALI) database (30) was searched for any available decision aids for pelvic exenteration. A search of the grey literature was also performed using Google Search ${ }^{\mathrm{TM}}$ engine. Separate searches were undertaken between the 8th January 2019 and 16th January 2019 using the following terms: 1) information about pelvic exenteration; 2) patient decision aid for pelvic exenteration; 3) treatment for advanced rectal cancer; 4) treatment for recurrent rectal cancer 5) information leaflet pelvic exenteration; 6) consent for pelvic exenteration; 7) decision making in pelvic exenteration.

The search results were limited to the first two pages, based on the assumption that internet users rarely go beyond the first page of search results (24). The articles were screened according to the eligibility criteria and all duplicates removed.

The eligibility criteria included sources that discussed surgical management of PE in LARC and LRRC that were aimed towards patients and written in English. Academic sources targeted for healthcare professionals, advertisements sponsored by Google and articles not written in the English language were excluded. Websites were viewed, screened for relevance and studies that did not meet the inclusion criteria were excluded. Sources assessed as potentially relevant were analysed further.

Sources were screened for appropriateness and checked for eligibility according to the defined inclusion criteria by two researchers $(A W)$ and $(A C)$. Any conflict between the two researchers were resolved by a third party, (DH). Data were extracted using a predefined extraction spreadsheet on Excel® version 16.16.16. Data were extracted on the following domains: 1) Website Descriptor: descriptors URL, upload source, country of origin, format of website, and purpose of website; 2) Health condition: classification of disease (LRRC, LARC); 3) Decision-making: Description of surgical options, description of oncological treatments, comparison of surgery versus no surgery, benefits and risks of surgery, and a description of the preoperative and recovery periods, length of recovery, prognosis, quality of life (QoL), pain and complications.

To determine whether the identified patient information sources qualified as a PDA they were assessed according to the criteria published by International Patient Decision Aid (IPDAS) Collaboration (31). This tool assesses the quality 
of PDAs in terms of their development process and shared decision-making design components (32). The IPDAS assessment of PDAs is reported in three categories: Qualifying (6 items), Certifying (10 items) and Quality (28 items). Only Qualifying and Certifying domains are mandatory to define a decision aid therefore sources were judged solely on these domains. The Qualifying criteria are required in order for an intervention to be considered a decision aid whilst the Certifying criteria ensure the decision aid has no harmful bias. Items 7-10 in the Certifying criteria were not applicable to this study due to its relevance for screening tests and therefore were excluded from analysis.

The quality of the written health information was assessed using the validated DISCERN tool (33). DISCERN has been designed to help users of consumer health information determine the quality of written information about treatment choices $(34,35)$. The tool is formed from 16 questions; the first 8 questions assess the reliability of the publication and the latter 8 , assess the quality of information on treatment choice. Each question rated the information on a 5-point scale ranging from No to Yes. The rating scale has been designed to help decide whether the quality criterion in question is present or has been 'fulfilled' by the publication. The global score indicates the assessor's overall conclusion of the quality of the source in providing written health information and can only be scored a 1,3 , or 5 .

Readability was assessed using the Flesch-Kincaid reading ease score using an online tool $(36,37)$. Readability is scored 0-100 and corresponds inversely with school years. The challenge in using the Flesch-Kincaid Reading Ease is that test results are not immediately meaningful and a conversion table is needed to make sense of the score (37). These difficulties were rectified by implementing the Flesch-Kincaid Grade Level which calculates a score that is proportional to school years i.e. grade 1, UK school year 2 age 6-7, grade 2, UK school year 3 age $7-8$. The results of the two tests correlate approximately inversely: a text with a comparatively high score on the Reading Ease test should have a lower score on the Grade-Level test.

\section{Results}

The DALI database identified six PDA's for colorectal cancer, all of which were ineligible for pelvic exenteration (30). A Google search for PDA's yielded 27,782,200 potential sources, of which 131 sources fulfilled the eligibility criteria. Ninety-nine sources were screened, of which 19 were excluded as advertisements. Eighty sources were subsequently assessed for eligibility. Seventy-four sources were excluded for the following reasons: 22 sources did not mention PE within the information; 24 sources were not aimed at LRRC/LARC; 25 sources were not written for patients and three sources had inaccessible websites at the time of analysis. Six sources were therefore eligible for inclusion (Fig. 1).

The six eligible sources were designated webpages, varying between HTML and PDF format. The sources were: 1) Canadian Cancer Charity; 2) Oxford University Hospitals NHS Foundation Trust; 3) Texas Oncology; 4) MD Anderson Cancer Centre; 5) Comprehensive Cancer Centre; 6) London Northwest Healthcare Trust (38-43). All sources were produced from centres in the Western world including; three from the USA, two from the UK and one from Canada.

Two of the sources were PDF format and four were HTML format. Patient targeted information was uploaded by four hospital/specialty associations, one specialist cancer centre and one cancer charity (Table 1). 
Table 1

Eligible sources included in the analysis

\begin{tabular}{|c|c|c|c|c|c|}
\hline Source & Title of website & Format & Country & $\begin{array}{l}\text { Name of } \\
\text { Uploader }\end{array}$ & $\begin{array}{l}\text { Upload } \\
\text { source type }\end{array}$ \\
\hline http://www.cancer.ca & $\begin{array}{l}\text { Pelvic } \\
\text { exenteration } \\
\text { Information for } \\
\text { patients and } \\
\text { their } \\
\text { families/carers }\end{array}$ & HTML & Canada & $\begin{array}{l}\text { Canadian } \\
\text { cancer charity }\end{array}$ & $\begin{array}{l}\text { Cancer } \\
\text { charity }\end{array}$ \\
\hline https://www.ouh.nhs.uk & $\begin{array}{l}\text { Pelvic exenteration } \\
\text { Information }\end{array}$ & PDF & UK & $\begin{array}{l}\text { Oxford } \\
\text { University } \\
\text { Hospitals NHS } \\
\text { Foundation }\end{array}$ & $\begin{array}{l}\text { Hospital/ } \\
\text { specialty } \\
\text { association }\end{array}$ \\
\hline https://www.texasoncology.com & $\begin{array}{l}\text { Recurrent rectal } \\
\text { cancer }\end{array}$ & HTML & US & $\begin{array}{l}\text { Texas } \\
\text { Oncology }\end{array}$ & $\begin{array}{l}\text { Hospital/ } \\
\text { speciality } \\
\text { association }\end{array}$ \\
\hline https://www.mdanderson.org & $\begin{array}{l}\text { Locally recurrent } \\
\text { rectal cancer }\end{array}$ & HTML & US & $\begin{array}{l}\text { MD Anderson } \\
\text { Cancer Centre }\end{array}$ & $\begin{array}{l}\text { Hospital/ } \\
\text { speciality } \\
\text { association }\end{array}$ \\
\hline http://cancer.unm.edu & $\begin{array}{l}\text { Recurrent rectal } \\
\text { cancer }\end{array}$ & HTML & US & $\begin{array}{l}\text { Comprehensive } \\
\text { cancer centre }\end{array}$ & $\begin{array}{l}\text { Cancer } \\
\text { centre }\end{array}$ \\
\hline http://www.stmarkshospital.nhs.uk & $\begin{array}{l}\text { complex cancer } \\
\text { surgery for men }\end{array}$ & PDF & UK & $\begin{array}{l}\text { London } \\
\text { Northwest } \\
\text { Healthcare } \\
\text { Trust }\end{array}$ & $\begin{array}{l}\text { Hospital/ } \\
\text { speciality } \\
\text { association }\end{array}$ \\
\hline
\end{tabular}

All sources provided information about LRRC or LARC, with half of the information sources focusing on LRRC alone. Description of surgical options and oncological treatments were reported in the majority of sources $(n=5)$. Five sources did not discuss the comparison of surgery vs no surgery nor the overall prognosis. Quality of life, benefits and risks of surgery, description of the preoperative and recovery periods, length of recovery, nor pain were discussed in 4 of the 6 sources. Half of the sources mentioned surgical complications within their information (Table 2). 
Table 2

Decision making domains discussed within the identified sources.

\begin{tabular}{|c|c|c|c|c|c|c|}
\hline SOURCE & $\mathrm{CaCC}$ & OUHNF & TO & MDACC & CCC & LNHT \\
\hline Classification of disease (LRRC LARC) & $\begin{array}{l}\text { LARC } \\
\text { LRRC }\end{array}$ & $\begin{array}{l}\text { LARC } \\
\text { LRRC }\end{array}$ & LRRC & LRRC & LRRC & $\begin{array}{l}\text { LARC } \\
\text { LRRC }\end{array}$ \\
\hline Description of surgical options & Yes & No & Yes & Yes & Yes & Yes \\
\hline Description of oncological treatments & No & Yes & Yes & Yes & Yes & Yes \\
\hline Comparison surgery vs no surgery & No & No & No & No & No & Yes \\
\hline Benefits and risks of surgery & Yes & No & No & No & No & Yes \\
\hline $\begin{array}{l}\text { Description of the preoperative and recovery } \\
\text { periods }\end{array}$ & No & Yes & No & No & No & Yes \\
\hline Length of recovery & No & Yes & No & No & No & Yes \\
\hline Prognosis & No & No & No & No & No & No \\
\hline Quality of life & Yes & No & No & No & No & Yes \\
\hline Pain & No & Yes & No & No & No & Yes \\
\hline Complications & Yes & Yes & No & No & No & Yes \\
\hline \multicolumn{7}{|c|}{$\begin{array}{l}\text { (Abbreviations: CaCC - Canadian Cancer Charity, OUHNF- Oxford University Hospitals NHS Foundation, TO - Texas } \\
\text { Oncology, MDACC - MD Anderson Cancer Centre, CCC - Comprehensive Cancer Centre, LNHT - London Northwest } \\
\text { Healthcare Trust }\end{array}$} \\
\hline
\end{tabular}

\section{International Patient Decision Aid Standards}

The information was inadequate when assessed according to the IPADS criteria, with no source identified as a decision aid. London Northwest Healthcare Trust met the highest number of IPADS criteria; fulfilling 5 out of 12 requirements. The median score was 3.5 for all identified sources (Table 3). All sources described the health condition for which an index decision is required. No source described the positive or negative features of each option, showed positive and negative features of options with equal detail, provided information about the funding source used for development nor provided information about the level of uncertainty around outcome probabilities. Five of the sources did not provide information of a future review to update the current information. Half of the sources explicitly stated the decision under consideration and described the treatment options available for the index decision. Four of the 6 sources did not describe the features of available treatment options available to help patients imagine the physical, social and/or psychological effects. Four of the 6 sources provided citations to the evidence provided. 
Table 3

IPDASi criteria for each source identified.

\begin{tabular}{|c|c|c|c|c|c|c|}
\hline IPDASi & Caccc & OUHNF & TO & MDACC & CCC & LNHT \\
\hline \multicolumn{7}{|l|}{ Qualifying } \\
\hline $\begin{array}{l}\text { Describes health condition or problem for which index } \\
\text { decision is required }\end{array}$ & Yes & Yes & Yes & Yes & Yes & Yes \\
\hline $\begin{array}{l}\text { Explicitly states decision under consideration (index } \\
\text { decision) }\end{array}$ & No & No & Yes & no & Yes & Yes \\
\hline Describes the options available for the index decision & No & No & Yes & Yes & Yes & No \\
\hline Describes the positive features of each option & No & No & No & No & No & No \\
\hline Describes the negative features of each option & No & No & No & No & No & No \\
\hline $\begin{array}{l}\text { Describes the features of options to help patients } \\
\text { imagine: the physical, social and/or psychological } \\
\text { effects }\end{array}$ & No & Yes & No & No & No & Yes \\
\hline \multicolumn{7}{|l|}{ Certification } \\
\hline $\begin{array}{l}\text { Shows positive and negative features of options with } \\
\text { equal detail }\end{array}$ & No & No & No & No & No & No \\
\hline $\begin{array}{l}\text { Provides information about the funding source used for } \\
\text { development }\end{array}$ & No & No & No & No & No & No \\
\hline Provides citations to the evidence selected & Yes & No & Yes & Yes & Yes & No \\
\hline Provides a production or publication date & No & Yes & No & No & No & Yes \\
\hline Provides information about update policy & No & No & No & No & No & Yes \\
\hline $\begin{array}{l}\text { Provides information about the level of uncertainty } \\
\text { around outcome probabilities }\end{array}$ & No & No & No & No & No & No \\
\hline Total Score: criteria discussed (/12) & 2 & 3 & 4 & 3 & 4 & 5 \\
\hline Percentage of criteria discussed & $17 \%$ & $35 \%$ & $25 \%$ & $25 \%$ & $35 \%$ & $42 \%$ \\
\hline
\end{tabular}

Abbreviations: CaCC - Canadian Cancer Charity, OUHNF- Oxford University Hospitals NHS Foundation, TO - Texas Oncology, MDACC - MD Anderson Cancer Centre, CCC - Comprehensive Cancer Centre, LNHT - London Northwest Healthcare Trust.

\section{DISCERN}

The quality of the written information provided by all information sources was acceptable, with all sources scoring a global score of 3 on the DISCERN tool (Table 4). Despite the acceptable quality of the written information, there was significant variation in reliability (score range 18-34) and quality of information (score range 11-22) provided. The majority of sources did not have clear aims or report when the publication was produced. Four of the 6 sources met the criteria for relevance and provided details of additional information. Half of the sources did not meet the criteria for: source of information used to compile the publication; reference the areas of uncertainty the benefits and risks of each treatment described; or explain how treatment choices would affect quality of life. Five of 6 sources were scored 4-5 for their balanced and unbiased representation of information. All sources were scored $1-3$ for description of 
how each treatment works. Two sources did not meet the criteria for clarity on whether there may be more than one possible treatment choice available.

Table 4

DISCERN assessment of each source identified (answers : 1 no, 3 partially, 5 yes)

\begin{tabular}{|c|c|c|c|c|c|c|}
\hline & $\mathrm{CaCC}$ & OUHNF & TO & MDACC & CCC & LNHT \\
\hline 1. Are the aims clear? & 3 & 1 & 1 & 1 & 1 & 5 \\
\hline 2. Does it achieve its aims? & 3 & 1 & 1 & 1 & 1 & 5 \\
\hline 3. Is it relevant? & 5 & 5 & 5 & 3 & 5 & 5 \\
\hline $\begin{array}{l}\text { 4. Is it clear what sources of information were used to } \\
\text { compile the publication? }\end{array}$ & 5 & 1 & 3 & 1 & 3 & 1 \\
\hline $\begin{array}{l}5 . \text { Is it clear when the information used or reported in the } \\
\text { publication was produced? }\end{array}$ & 1 & 1 & 1 & 3 & 1 & 5 \\
\hline 6. Is it balanced and unbiased? & 4 & 4 & 5 & 3 & 5 & 5 \\
\hline $\begin{array}{l}\text { 7. Does it provide details of additional sources of support } \\
\text { and information? }\end{array}$ & 5 & 5 & 1 & 5 & 1 & 5 \\
\hline 8. Does it refer to areas of uncertainty? & 1 & 1 & 3 & 1 & 3 & 3 \\
\hline 9. Does it describe how each treatment works? & 2 & 3 & 3 & 1 & 3 & 3 \\
\hline 10.Does it describe the benefits of each treatment? & 1 & 1 & 3 & 1 & 3 & 3 \\
\hline 11. Does it describe the risks of each treatment? & 3 & 3 & 1 & 1 & 1 & 3 \\
\hline $\begin{array}{l}\text { 12. Does it describe what would happen if no treatment is } \\
\text { used? }\end{array}$ & 1 & 1 & 1 & 1 & 1 & 4 \\
\hline $\begin{array}{l}\text { 13. Does it describe how the treatment choices affect } \\
\text { overall quality of life? }\end{array}$ & 3 & 3 & 1 & 1 & 1 & 3 \\
\hline $\begin{array}{l}\text { 14. Is it clear that there may be more than one possible } \\
\text { treatment choice? }\end{array}$ & 1 & 1 & 4 & 5 & 4 & 5 \\
\hline 15. Does it provide support for shared decision-making? & 1 & 1 & 1 & 1 & 1 & 1 \\
\hline $\begin{array}{l}\text { 16. Based on the answers to all of the above questions, } \\
\text { rate the overall quality of the publication as a source of } \\
\text { information about treatment choices. }\end{array}$ & 3 & 3 & 3 & 3 & 3 & 3 \\
\hline \multicolumn{7}{|c|}{$\begin{array}{l}\text { Abbreviations: CaCC - Canadian Cancer Charity, OUHNF- Oxford University Hospitals NHS Foundation, TO - Texas } \\
\text { Oncology, MDACC - MD Anderson Cancer Centre, CCC - Comprehensive Cancer Centre, LNHT - London Northwest } \\
\text { Healthcare Trust. }\end{array}$} \\
\hline
\end{tabular}

\section{Readability}

The average reading age of the UK population is 11 years (44) yet patient information is recommended to be written at a level of a 14 year old (45). The median Flesch-Kincaid reading ease was 50.85 (32.5-80.8). This equates to $10-$ 12th grade reading, age 15-18 years i.e. fairly difficult to read. The median Flesch-Kincaid grade level score was 7.65 (3-9.7), age $13-14$ reading age (Table 5). 
Table 5

Flesch-Kincaid reading ease and grade for each source identified.

\begin{tabular}{|lllllll|}
\hline & CaCC & OUHNF & TO & MDACC & CCC & LNHT \\
\hline Flesch-Kincaid Reading ease & 53.5 & 80.8 & 48.2 & 40.9 & 32.5 & 79.7 \\
\hline Flesch-Kincaid Reading ease grade equivalent & $10-12$ & 6 & College & College & College & 7 \\
\hline Flesch-Kincaid Reading Grade level & 7.5 & 3.5 & 7.8 & 9.3 & 9.7 & 3 \\
\hline $\begin{array}{l}\text { Abbreviations: CaCC - Canadian Cancer Charity, OUHNF- Oxford University Hospitals NHS Foundation, TO - Texas } \\
\text { Oncology, MDACC - MD Anderson Cancer Centre, CCC - Comprehensive Cancer Centre, LNHT - London Northwest } \\
\text { Healthcare Trust. }\end{array}$
\end{tabular}

\section{Discussion}

This is the first review of the literature to focus exclusively on the information available to patients with LRRC or LARC who require PE. There are no PDA's and limited online resources available to assist patients in this particular decision-making process. Most of the available information is of poor quality and does not aid patient decisionmaking, as reflected in low DISCERN and IPDAS scores.

From a patient's perspective, the decision whether to undergo PE surgery is complex. Patients require support to understand the proposed care, treatment and non-operative options available. Supplied information must include the risks, benefits and consequences of treatment options in order for them to make an informed decision and participate in SDM. The principal concept of SDM is a joint decision made between a clinician and an informed patient without the use of the internet, however, patients continue to access online health information for education. None of the sources in this study described how life would change after surgery in detail. The consequences of exenterative surgery, length of recovery, QOL and post-operative pain were only discussed in 2 available resources and complications in 3 resources. SDM cannot be achieved with such limited evidence based-literature available. With 2 resources not comparing all available treatment options and not discussing risks and benefits associated with each option, a balanced decision based on the information away from the consultation is impossible. Without a PDA or reliable evidence-based literature, patients have no other alternative than to use the internet which currently has poor content.

Less than half of the 12 IPDAS criteria were discussed in the available internet sources. London Northwest Healthcare Trust currently has the most informative piece of literature, however, only met $42 \%$ of the IPDASi criteria. This resource lacks sufficient balanced detail to qualify as a decision aid and insufficient information to exclude any harmful bias. The overall quality of all sources was adequate according to the DISCERN tool. The lack of high-quality patient information is not limited to LARC/LRRC. Poor quality online health information about other conditions including perianal Crohn's fistulae (46), ulcerative colitis (47), breast surgery (48) and full thickness rectal prolapse surgery (49) have been reported. This is alarming when so many patients turn to online resources and trust these sources of information.

The readability assessment of online health information for PE surgery is not patient-friendly with a median FleschKincaid reading ease of 50.85. Information should be aimed towards the lowest health literate patient in order to support patients to understand their treatment options and what is known of the benefits, harms, consequences and burdens of those options. The text intended for readership by the general public should aim for a schooling age 13- 
14 years (36) and some of the literature analysed in this study required the reader to have attended University to understand the text. Further efforts are required to invest in health literate decision support materials and ensure that healthcare professionals tailor conversations to take account potential low health literacy.

Limitations of the study include non-inclusion of printed PDAs that individual health care providers have produced but which aren't available on the internet. Further limitations were that searches were limited to the first two pages and a more extensive search may have resulted in more literature. TO and CCC literature were analysed separately for this study as they were identified as different websites with different descriptors, URL, upload source and purpose. However, the content and layout of both were very similar which may introduce some bias to the results.

The importance of PDAs in clinical practice has been acknowledged by NICE, who have developed 39 decision aids which cover conditions that may be surgically treated, including breast cancer, hip and knee osteoarthritis and gynaecological procedures (50). Whilst there are a few surgically based NICE PDAs available, the majority have been developed for conditions usually managed medically for example atrial fibrillation, coronary heart disease, stroke, heartburn, dementia etc. Despite the increasing acceptance and use of PDA's, as things stand, currently nothing exists for patients specifically diagnosed with LARC or LRRC. It is evident from the literature there is a clear need for accurate and informative PDA highlighting the risks, benefits and range of treatments available to these patients.

\section{Conclusion}

Current online health information relating to PE surgery for LARC or LRRC is of limited use in aiding patient decisionmaking, as reflected in low DISCERN and IPDAS scores. The current information available is scant and of variable but predominantly poor quality. Given the peri-operative morbidity and mortality risks of PE surgery and lifelong QOL implications, there is a need to develop and disseminate high quality information to facilitate SDM. Further studies need to determine whether local literature is being used at different centres and given the complexity of the decision making, ideally a universally acceptable PDA should be developed.

\section{List Of Abbreviations}

CaCC - Canadian Cancer Charity

CCC - Comprehensive Cancer Centre

DALI - Decision Aid Library Inventory

EBPI - Evidence based patient information

IPDAS - International Patient Decision Aid Collaboration

LARC - Locally Advanced Rectal Cancer

LNHT - London Northwest Healthcare Trust

LRRC - Locally Recurrent Rectal Cancer

MDACC - MD Anderson Cancer Centre

OUHNF- Oxford University Hospitals NHS Foundation

Page 10/15 
PDA - Patient Decision Aid

PE - Pelvic exenteration

PRISMA - Preferred Reporting Items for Systematic Reviews and Meta-analyses

RCSEng - Royal College of Surgeons of England

SDM - Shared Decision Making

TO - Texas Oncology

\section{Declarations}

\section{Availability of data and materials}

The datasets used and/or analysed during the current study are aviable form the corresponding author on reasonable request.

\section{Ethics approval and Consent to Participate}

Ethical approval was obtained for this study by NHS Grampian, North of Scotland Research Ethics Service. IRAS 257890.

\section{Consent for publication}

All authors consent to this publication.

\section{Competing interests}

The authors declare that they have no financial or non-financial competing interests.

\section{Funding}

The authors deny any source of funding for the development of this work.

\section{Author's contributions}

AW \& AC performed relevant searches and screened sources for appropriateness and checked for eligibility. AW was a major contributor in writing this paper. AC participated in the writing of this paper. $\mathrm{DAH}, \mathrm{HH}, \mathrm{DH}$ and MDE all participated in establishing the development of this study and achieving ethical approval. DAH HH and AC contributed to the editing of this paper. DH and MDE were major contributors in the editing of this paper. All authors read and approved the final manuscript.

\section{Acknowledgements}

Not applicable

\section{Author details}

Anwen Williams ${ }^{1,2}$; drawilliams@hotmail.co.uk, anwen.williams3@wales.nhs.uk 
Andrew Cunningham ${ }^{1,2}$; andrew.cunnigham@wales.nhs.uk

Hayley Hutchings $\mathrm{H}^{2}$; h.a.hutchings@swansea.ac.uk

Dean Harris ${ }^{1}$; dean.a.harris@wales.nhs.uk

Deena Harji ${ }^{3}$; deena.harji@nhs.net

Martyn Evans ${ }^{1}$; martyn.evans@wales.nhs.uk

${ }^{1}$ Department of Surgery, Swansea Bay University Health Board, Singleton Hospital, Swansea. SA2 8QA.

${ }^{2}$ Swansea University Medical School, Institute of Life Science 2. Swansea. SA2 8QA.

${ }^{3}$ Population Health Sciences, University of Newcastle and Royal Victoria Infirmary, Newcastle upon Tyne. NE2 4HH

\section{References}

1. Bray F, Ferlay J, Soerjomataram I, Siegel RL, Torre LA, Jemal A. Global cancer statistics 2018: GLOBOCAN estimates of incidence and mortality worldwide for 36 cancers in 185 countries. CA Cancer J Clin. 2018;68(6):394-424.

2. Consensus statement on the multidisciplinary management of patients with recurrent and primary rectal cancer beyond total mesorectal excision planes. Br J Surg. 2013;100(8):1009-14.

3. Sineshaw HM, Jemal A, Thomas CR, Jr., Mitin T. Changes in treatment patterns for patients with locally advanced rectal cancer in the United States over the past decade: An analysis from the National Cancer Data Base. Cancer. 2016;122(13):1996-2003.

4. Sebag-Montefiore D, Stephens RJ, Steele R, Monson J, Grieve R, Khanna S, et al. Preoperative radiotherapy versus selective postoperative chemoradiotherapy in patients with rectal cancer (MRC CR07 and NCIC-CTG C016): a multicentre, randomised trial. Lancet. 2009;373(9666):811-20.

5. Kapiteijn E, Marijnen CA, Nagtegaal ID, Putter H, Steup WH, Wiggers T, et al. Preoperative radiotherapy combined with total mesorectal excision for resectable rectal cancer. N Engl J Med. 2001;345(9):638-46.

6. Ikoma N, You YN, Bednarski BK, Rodriguez-Bigas MA, Eng C, Das P, et al. Impact of Recurrence and Salvage Surgery on Survival After Multidisciplinary Treatment of Rectal Cancer. J Clin Oncol. 2017;35(23):2631-8.

7. Solum AM, Riffenburgh RH, Johnstone PA. Survival of patients with untreated rectal cancer. Journal of surgical oncology. 2004;87(4):157-61.

8. Yang TX, Morris DL, Chua TC. Pelvic exenteration for rectal cancer: a systematic review. Dis Colon Rectum. 2013;56(4):519-31.

9. Kusters M, Austin KK, Solomon MJ, Lee PJ, Nieuwenhuijzen GA, Rutten HJ. Survival after pelvic exenteration for T4 rectal cancer. Br J Surg. 2015;102(1):125-31.

10. Radwan RW, Jones HG, Rawat N, Davies M, Evans MD, Harris DA, et al. Determinants of survival following pelvic exenteration for primary rectal cancer. Br J Surg. 2015;102(10):1278-84.

11. Temple WJ, Saettler EB. Locally recurrent rectal cancer: role of composite resection of extensive pelvic tumors with strategies for minimizing risk of recurrence. Journal of surgical oncology. 2000;73(1):47-58. 
12. Yamada K, Ishizawa T, Niwa K, Chuman Y, Akiba S, Aikou T. Patterns of pelvic invasion are prognostic in the treatment of locally recurrent rectal cancer. Br J Surg. 2001;88(7):988-93.

13. Heriot AG, Byrne CM, Lee P, Dobbs B, Tilney $H$, Solomon MJ, et al. Extended radical resection: the choice for locally recurrent rectal cancer. Dis Colon Rectum. 2008;51(3):284-91.

14. Austin KK, Solomon MJ. Pelvic exenteration with en bloc iliac vessel resection for lateral pelvic wall involvement. Dis Colon Rectum. 2009;52(7):1223-33.

15. Milne T, Solomon MJ, Lee P, Young JM, Stalley P, Harrison JD. Assessing the impact of a sacral resection on morbidity and survival after extended radical surgery for locally recurrent rectal cancer. Ann Surg. 2013;258(6):1007-13.

16. Nelson AM, Albizu-Jacob A, Fenech AL, Chon HS, Wenham RM, Donovan KA. Quality of life after pelvic exenteration for gynecologic cancer: Findings from a qualitative study. Psychooncology. 2018.

17. Kecmanovic DM, Pavlov MJ, Kovacevic PA, Sepetkovski AV, Ceranic MS, Stamenkovic AB. Management of advanced pelvic cancer by exenteration. European journal of surgical oncology : the journal of the European Society of Surgical Oncology and the British Association of Surgical Oncology. 2003;29(9):743-6.

18. Yamada K, Ishizawa T, Niwa K, Chuman Y, Aikou T. Pelvic exenteration and sacral resection for locally advanced primary and recurrent rectal cancer. Dis Colon Rectum. 2002;45(8):1078-84.

19. Coulter A, Stilwell D, Kryworuchko J, Mullen PD, Ng CJ, van der Weijden TJBMI, et al. A systematic development process for patient decision aids. 2013;13(2):S2.

20. An introduction to patient decision aids. Bmj. 2013;347:f4147.

21. England RCoS. Consent: Supported decision-making - a good practice guide. https://wwwrcsengacuk/libraryand-publications/college-publications/docs/consent-good-practice-guide/. 2016. Accessed 18 ${ }^{\text {th }}$ December 2019.

22. online FSHToiulfhi. Health Topics: $80 \%$ of internet users look for health information online. http://wwwpewinternetorg/files/oldmedia/Files/Reports/2011/PIP_Health_Topicspdf. 2011. Accessed 23 ${ }^{\text {rd }}$ January 2020.

23. Commission E. Europeans becoming enthusiastic users of online health information. https://eceuropaeu/digitalsingle-market/news/europeans-becoming-enthusiastic-users-online-health-information. 2014.

24. van Deursen AJ. Internet skill-related problems in accessing online health information. International journal of medical informatics. 2012;81(1):61-72.

25. Yli-Uotila T, Rantanen A, Suominen T. Online social support received by patients with cancer. Comput Inform Nurs. 2014;32(3):118-26; quiz 27-8.

26. Rimer BK, Lyons EJ, RibisI KM, Bowling JM, Golin CE, Forlenza MJ, et al. How new subscribers use cancer-related online mailing lists. Journal of medical Internet research. 2005;7(3):e32-e.

27. Asiedu GB, Eustace RW, Eton DT, Radecki Breitkopf C. Coping with colorectal cancer: a qualitative exploration with patients and their family members. Fam Pract. 2014;31(5):598-606.

28. Elwyn G, Frosch D, Thomson R, Joseph-Williams N, Lloyd A, Kinnersley P, et al. Shared decision making: a model for clinical practice. J Gen Intern Med. 2012;27(10):1361-7.

29. https://www.crd.york.ac.uk/PROSPERO/. Accessed 16 ${ }^{\text {th }}$ March 2019.

30. https://decisionaid.ohri.ca/azlist.html. Accessed 27 th $A$ pril 2019.

31. Elwyn G, O'Connor A, Stacey D, Volk R, Edwards A, Coulter A, et al. Developing a quality criteria framework for patient decision aids: online international Delphi consensus process. Bmj. 2006;333(7565):417. 
32. Elwyn G, O'Connor AM, Bennett C, Newcombe RG, Politi M, Durand MA, et al. Assessing the quality of decision support technologies using the International Patient Decision Aid Standards instrument (IPDASi). PLoS One. 2009;4(3):e4705.

33. http://www.discern.org.uk/general_instructions.php. Accessed $28^{\text {th }}$ November 2018.

34. Charnock D SS, Needham G, Gann R DISCERN: an instrument for judging the quality of written consumer health information on treatment choices. Journal of Epidemiology and Community Health. 1999;2(53):105-11.

35. D C. The DISCERN criteria : criteria for consumer health information. 1998.

36. https://readable.com/blog/the-flesch-reading-ease-and-flesch-kincaid-grade-level/.

37. https://en.wikipedia.org/wiki/Flesch-Kincaid_readability_tests\#cite_note-8.

38. http://www.cancer.ca/en/cancer-information/diagnosis-and-treatment/tests-and-procedures/pelvicexenteration/?region=on. Accessed $9^{\text {th }}$ January 2019.

39. https://www.ouh.nhs.uk/patient-guide/leaflets/files/13177Ppelvic.pdf. Accessed $11^{\text {th }}$ January 2019.

40. https://www.texasoncology.com/types-of-cancer/rectal-cancer/recurrent-rectal-cancer. Accessed $13^{\text {th }}$ January 2019.

41. https://www.mdanderson.org/publications/oncolog/aggressive-multimodality-salvage-therapy-for-locallyrecurrent-r.h13-1590624.html. Accessed 16 th January 2019.

42. http://cancer.unm.edu/cancer/cancer-info/types-of-cancer/rectal-cancer/recurrent-rectal-cancer/. Accessed $16^{\text {th }}$ January 2019.

43. http://www.stmarkshospital.nhs.uk/wp-content/uploads/2017/09/smh-patient-leaflets-cancer-surgery-formen.pdf. Accessed $13^{\text {th }}$ January 2019.

44. https://literacytrust.org.uk/information/what-is-literacy/. Accessed $2^{\text {nd }}$ June 2020.

45. National Institutes of Health. How to Write Easy to Read Health Materials. National Library of Medicine Web site. Available at: http://www.nlm.nih.gov/medlineplus/etr.html. Accessed $2^{\text {nd }}$ June 2020.

46. Marshall JH BD, Lee MJ, Jones GL, Lobo AJ, Brown SR. . Assessing internet-based information used to aid patient decision-making about surgery for perianal Crohn's fistula. . Tech Coloproctol. 2017;21(6):461-469. doi:10.1007/s10151-017-1648-2.

47. Baker DM, Marshall JH, Lee MJ, Jones GL, Brown SR, Lobo AJ. A Systematic Review of Internet Decision-Making Resources for Patients Considering Surgery for Ulcerative Colitis. Inflamm Bowel Dis. 2017;23(8):1293-300.

48. Bruce JG, Tucholka JL, Steffens NM, Neuman HB. Quality of online information to support patient decisionmaking in breast cancer surgery. Journal of surgical oncology. 2015;112(6):575-80.

49. Fowler GE, Baker DM, Lee MJ, Brown SR. A systematic review of online resources to support patient decisionmaking for full-thickness rectal prolapse surgery. Tech Coloproctol. 2017;21(11):853-62.

50. https://www.evidence.nhs.uk/search?om=[\%7B\%22ety\%22:

[\%22Patient\%20Decision\%20Aids\%22]\%7D]\&q=patient+information+leaflets\&sp=on. Accessed $12^{\text {th }}$ December 2018.

\section{Figures}


131 Sources identified through Google search

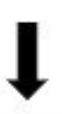

32 Excluded for Duplication

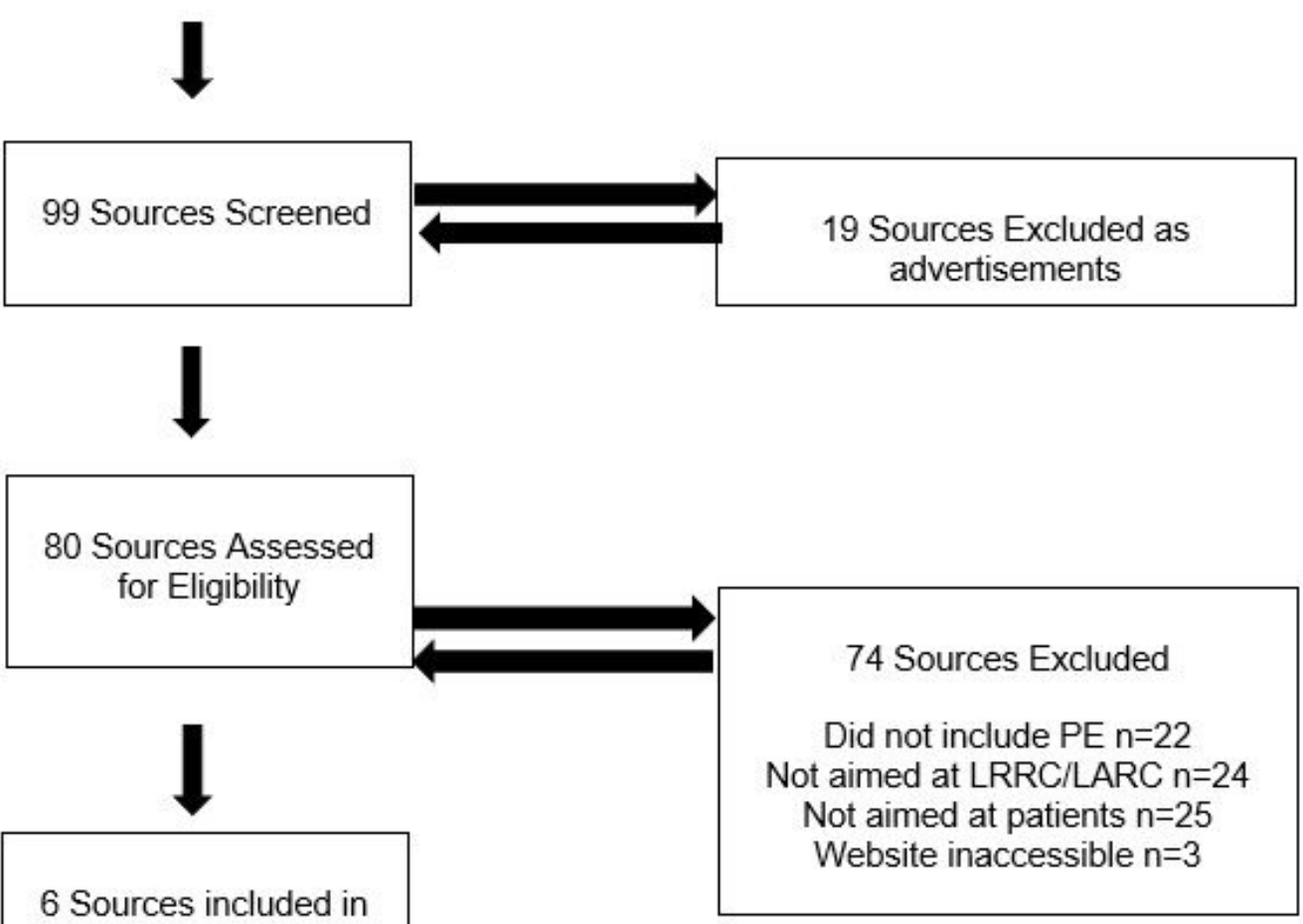
the analysis

Figure 1

PRISMA flowchart of study selection 